\title{
High-mobility group box 1 promotes early acute allograft rejection by enhancing IL-6-dependent Th17 alloreactive response
}

\author{
Lihua Duan ${ }^{1}$, Cong-Yi Wang ${ }^{2,3}$, Jie Chen ${ }^{1}$, Quan Gong ${ }^{1}$, Ping Zhu ${ }^{1}$, Fang Zheng ${ }^{1}$, Zheng Tan ${ }^{1}$, Feili Gong ${ }^{1}$ \\ and Min Fang ${ }^{1}$
}

Previously, we reported that extracellular high-mobility group box 1 (HMGB1) functions as an innate alarmin implicated in cardiac allograft acute rejection. We now present evidence suggesting that HMGB1 is pivotal in inducing interleukin-17 (IL-17)-producing alloreactive T cells by stimulating dendritic cells secretion of IL-6. Those IL-17 ${ }^{+} \mathrm{T}$ cells are likely to be the major effector cells responsible for the early stage of cardiac allograft rejection through mediating an influx of neutrophils into allografts, and therefore, blockade of IL-17A significantly prolonged murine cardiac allograft survival. In contrast to the classical model for a dominant role of IFN- $\gamma^{+}-$Th1 cells have in acute allograft rejection, our data suggest that IFN- $\gamma^{+}$-Th1 cells are responsible for the late stage of graft destruction by inducing monocyte infiltration when IL-17 ${ }^{+}$T-cell response recedes. Blockade of HMGB1 significantly decreased splenic alloreactive Th17 cells and IFN- $\gamma$-producing $\mathrm{CD}^{+}$T cells in the recipients, leading to less infiltration of neutrophils along with lower IL- 6 and IL-17 expression levels in the grafts as well as prolongation of cardiac allograft survival. Together, these data support a novel model in which HMGB1 induces IL-17-producing alloreactive T cells to mediate early stage of allograft rejection, whereas IFN- $\gamma$-producing alloreactive Th1 cells provoke graft destruction after Th17 response recedes.

Laboratory Investigation (2011) 91, 43-53; doi:10.1038/labinvest.2010.141; published online 16 August 2010

KEYWORDS: allograft rejection; HMGB1; Th17; transplantation

Th17 cells are a recently identified T-helper subset implicated in various inflammatory responses and in the pathogenesis of many autoimmune diseases. ${ }^{1,2}$ They are characterized as preferential producers of interleukin-17A (IL-17A), IL-17F, IL-21, and IL-22. ${ }^{3}$ Naive CD4 ${ }^{+} \mathrm{T}$ cells can be polarized into Th17 cells on antigen receptor ligation in the presence of IL- 6 and TGF- $\beta .{ }^{4,5}$ The orphan nuclear receptor ROR $\gamma t$ has been suggested to be responsible for the transcription of genes encoding IL-17 family cytokines, ${ }^{6}$ whereas $\mathrm{ROR} \alpha$ synergizes with $\mathrm{ROR} \gamma \mathrm{t}$ to promote differentiation and function of Th17 cells. ${ }^{7}$ In contrast, IL-23 expands differentiated Th17 cells or maintains IL-17 production, and IL-21 functions in an autocrine manner to promote Th17 cell differentiation along with TGF- $\beta{ }^{1,8}$ It is noteworthy that IL-6 controls Th17 immunity by inhibiting the conversion of naive $\mathrm{CD} 4{ }^{+} \mathrm{T}$ cells into Foxp $3^{+}$regulatory T cells. ${ }^{9}$
Unlike its well recognition in the pathogenesis of autoimmune disorders such as inflammatory bowel disease and multiple sclerosis, ${ }^{2,10-13}$ the exact role of Th17 response in allograft rejection largely remained enigmatic. Conventionally, Th1 cells and cytotoxic $\mathrm{CD}^{+} \mathrm{T}$ cells induced by alloantigen stimuli were thought to be important in allograft rejection. However, recent studies provided evidence suggesting a role for IL-17 in acute allograft rejection, ${ }^{14}$ and blockade of IL-17 action by an IL-17R/IgG-Fc fusion protein prolonged cardiac allograft survival. ${ }^{15}$ Patients undergone acute renal or lung allograft rejection were also found to be associated with increased IL-17 in the serum or bronchoalveolar lavage. ${ }^{16,17}$ Nevertheless, a comprehensive picture of Th17 cells in allograft rejection and their relationship with Th1 cells in the alloimmunity settings remained elusive.

\footnotetext{
${ }^{1}$ Laboratory of Transplantation, Department of Immunology, Tongji Medical College, Huazhong University of Science and Technology, Wuhan, China; ${ }^{2}$ The Center for Biomedical Research, Tongji Hospital, Tongji Medical College, Huazhong University of Science and Technology, Wuhan, China and ${ }^{3}$ Center for Biotechnology and Genomic Medicine, Medical College of Georgia, Augusta, GA, USA

Correspondence: Dr M Fang or F Gong, Laboratory of Transplantation, Department of Immunology, Tongji Medical College, Huazhong University of Science and Technology, Hangkong Road 13, Wuhan 430030, China.

E-mail: minfang89@mail.hust.edu.cn or flgong@163.com

Received 12 March 2010; revised 1 June 2010; accepted 6 June 2010
} 
High-mobility group box 1 (HMGB1) was originally characterized as a nuclear protein implicated in facilitating DNA binding. ${ }^{18}$ Recent studies have now consistently demonstrated that it also functions as a critical mediator to initiate innate immune response on inflammatory or other insults. HMGB1 can be either secreted by activated immune cells such as monocytes and macrophages or passively released by necrotic or damaged cells. ${ }^{19-21}$ Previously, we demonstrated a role for HMGB1 in the initiation and progression of allograft rejection. ${ }^{22}$ In this study, we sought to understand the role of HMGB1 in de novo generation of $\mathrm{IL}-17^{+} \mathrm{T}$ cells during acute allograft rejection. Our study data suggest that IL- $17^{+} \mathrm{T}$ cells could be essential for the early stage of allograft rejection by inducing an influx of neutrophils into allografts, whereas IFN- $\gamma^{+}-$Th1 cells are likely responsible for the late graft destruction by enhancing monocyte infiltrations after Th17 response recedes, and this process is tightly controlled by HMGB1 through regulation of IL-6 production from dendritic cells (DCs).

\section{MATERIALS AND METHODS \\ Animals}

BALB/c $\left(H-2^{d}\right)$ mice were obtained from the Animal Facility of Tongji Medical College, China. C57BL/6 $\left(H-2^{b}\right)$ mice were purchased from the Institute of Organ Transplantation of Tongji Hospital, China. $\mathrm{C} 3 \mathrm{H} / \mathrm{HeOuj}$ mice were purchased from the Jackson Laboratory. Female mice (6- to 8-week old, body weight $20-30 \mathrm{~g}$ ) were used for the study. The mice were bred and maintained in a specific pathogen-free barrier facility. All the studies were performed in compliance with the Tongji Medical College Animal Care and Use Committee guidelines.

\section{Antibodies and Reagents}

Expression and purification of mouse recombinant HMGB1 (rHMGB1) were carried out as previously described. ${ }^{22}$ LPS contamination in purified rHMGB1 was less than $4 \mathrm{pg} / \mu \mathrm{g}$ protein as determined by endotoxin-specific chromogenic limulus test (Seikagaku Corporation, Tokyo, Japan). HMGB1 antibodies (Abs) were produced by immunizing New Zealand white rabbits with rHMGB1 and Abs with neutralizing activities were tested as reported. ${ }^{23}$ Affinity-purified anti$\mathrm{CD} 8 \alpha$ (clone 53-6.7) and IL-17A-neutralizing mAb (clone TC11-18H10.1) and control rat IgG were purchased from Biolegend (San Diego, CA, USA). FITC-labeled anti-CD4 (clone GK1.5), FITC-labeled anti-CD8 $\alpha$ (53-6.7), PE-labeled anti-IFN- $\gamma$, PE-labeled anti-IL-17 (clone TC11-18H10), and purified rat anti-mouse CD4 (clone RM4-5) were purchased from BD Pharmingen (San Jose, CA, USA). IL-6-blocking $\mathrm{Ab}$ (clone MP5-20F3), Gr-1 (clone RB6-8C5), F4/80 (clone BM8), PE-Cy5-labeled anti-mouse CD4 (GK1.5), and anti$\mathrm{CD} 8 \alpha$ (53-6.7) were purchased from eBioscience (San Diego, CA, USA). LPS and mitomycin were obtained from SigmaAldrich (Saint Louis, MO, USA).

\section{Cardiac Allograft Transplantation and HMGB1- or IL-17-Neutralizing Ab Administration}

C57BL/6 $\left(H-2^{b}\right)$ mice were used as recipients and BALB/c $\left(H-2^{d}\right)$ mice were used as donors. BALB/c to $\mathrm{BALB} / \mathrm{c}$ mice were used as the combination of syngeneic grafts transplantation. Heterotopic cardiac transplantation and assessment of allograft function were conducted as described previously. ${ }^{24}$ Briefly, the cardiac allograft was transplanted in the abdominal cavity by anastomosing the aorta and pulmonary artery of the graft end-to-side to the recipient's aorta and vena cava, respectively. Allograft function was assessed by daily palpation of the abdomen. Rejection was defined as complete cessation of cardiac contractility as determined by direct visualization. HMGB1-neutralizing Ab (600 $\mu \mathrm{g}$ per mouse) was intraperitoneally (i.p.) injected daily into recipients from the day before transplantation till day 3 or day 4 after transplantation. Recipients received same amount of normal rabbit IgG (Sigma-Aldrich) were served as controls. IL-17A-neutralizing mAb (100 $\mu \mathrm{g}$ per mouse) was administered to each recipient i.p. from the day of transplantation until day 3 after transplantation. Mice receiving same amount of rat IgG were used as controls. Allograft survival was present as mean survival time (MST).

\section{Ex Vivo Stimulation of Splenic T Cells of Recipients by Donor Splenocytes and Analysis of Cytokine Production} The heart allografts from $\mathrm{BALB} / \mathrm{c}$ donor mice were transplanted into C57BL/6 or BALB/c recipient mice, splenocytes ( $n \geq 3$ mice per time point) from recipients were then prepared at days 1, 3, 5, and 7 after transplantation. Splenocytes were stimulated for $4.5 \mathrm{~h}$ in the presence of $50 \mathrm{ng} / \mathrm{ml}$ PMA, $1 \mu \mathrm{g} / \mathrm{ml}$ ionomycin, and $2 \mu \mathrm{M}$ monensin (all from SigmaAldrich) at $37^{\circ} \mathrm{C}$ under $5 \% \mathrm{CO}_{2}$. To determine the allospecificity of IL-17 productions by splenic $\mathrm{T}$ cell, splenic T cells were subjected to ex vivo stimulation by donor (BALB/c) or third party $(\mathrm{C} 3 \mathrm{H} / \mathrm{HeOuj})$ splenocytes (which were treated with mitomycin and labeled with CFSE to distinguish from the splenic $\mathrm{T}$ cells of recipients) for 5 days with or without additional $4.5 \mathrm{~h}$ activation by PMA and ionomycin in the presence of monensin. The cells were then stained for surface markers followed by labeling with specific cytokine Abs or isotype controls. Intracellular cytokine production was then analyzed by flow cytometry on FACSCalibur (BD Biosciences, Mountain View, CA, USA) using CellQuest software (BD Biosciences) as instructed.

\section{SYBR Green Real-Time RT-PCR}

The recipient mice were killed at indicated time after transplantation. Cardiac allografts were collected and subjected to RNA isolation using the TRIzol (Invitrogen, Carlsbad, CA, USA) reagent according to the manufacturer's instruction. cDNA was synthesized from $2 \mu \mathrm{g}$ RNA using a first-strand DNA synthesis kit (Fermentas Life Sciences, St Leon-Rot, Germany). The mRNA levels for HMGB1, IL-6, IL-17, and IFN $-\gamma$ in the grafts were analyzed by real-time PCR using 
iCycler (Bio-Rad). PCR reaction mixture was prepared using SYBR Premix Ex Taq (TaKaRa) according to the manufacturer's instructions. Primers for PCR amplification were as follows: HMGB1, 5'-GCGGACAAGGCCCGTTA-3', 5'-AGA GGAAGAAGGCCGAAGGA- $3^{\prime}$; IFN- $\gamma, 5^{\prime}$-AGCGGCTGACTG AACTCAGATTGTAG- $3^{\prime}, 5^{\prime}$-GTCACAGTTTTCAGCTGTATA GGG-3'; IL-6, 5'-GAGACTTCCATCCAGTTGCC-3' ${ }^{\prime}$, 5'-AAG TGCATCATCGTTGTTCATACA-3'; IL-17A, 5'-GACCAGGA TCTCTTGCTGGA-3' ${ }^{\prime}, 5^{\prime}$-GGACTCTCCACCGCAATGA- $3^{\prime}$, and GAPDH, 5' ${ }^{\prime}$-TTCACCACCATGGAGAAGGC- $3^{\prime}, 5^{\prime}$-GGCATG GACTGTGGTCATGA- $3^{\prime}$. Relative expression levels for cytokines were normalized by GAPDH and calculated by using the $2^{-\Delta \Delta C t}$ method and expressed in arbitrary units. The expression of each cytokine in normal mice was used as calibrator.

\section{Histological and Immunohistochemical Analyses}

Hematoxylin/eosin staining was used to assess the pathological changes of sections derived from cardiac allografts. Tissue sections were also double stained for CD4 and IL-17 for analysis of in situ allograft-infiltrating $\mathrm{CD} 4{ }^{+} \mathrm{IL}-17^{+}$ $\mathrm{T}$ cells using the established techniques. ${ }^{22,24}$ To identify the cell types of infiltrates in the allogeneic or syngeneic cardiac grafts, we stained tissue sections for CD4, CD8, Gr-1, or F4/ 80 by immunohistochemical staining method. Briefly, after deparaffinization and rehydration, the sections were treated with $3 \% \mathrm{H}_{2} \mathrm{O}_{2}$ followed by blocking with $10 \%$ goat serum in PBS. The sections were then stained for CD4, CD8, Gr-1, or F4/80 overnight at $4^{\circ} \mathrm{C}$. The numbers of positive cells were counted on five randomly chosen fields of graft sections in each animal at 200-fold magnification, by an examiner without any prior knowledge of the experimental procedures. The counts are normalized to tissue area and are shown in $\mathrm{mm}^{2}$.

\section{Generation of BMDCs and MLC}

Bone-marrow-derived dendritic cells (BMDCs) were generated from bone marrow cells in the presence of GM-CSF and IL-4 as reported. ${ }^{25}$ After 7 days of culture, the cells were stimulated with rHMGB1 $(5 \mu \mathrm{g} / \mathrm{ml})$ or LPS $(500 \mathrm{ng} / \mathrm{ml})$ for $18 \mathrm{~h}$ to induce IL-6 secretion. For mixed lymphocyte culture (MLC), $5 \times 10^{6} \mathrm{C} 57 \mathrm{BL} / 6 \mathrm{~T}$ cells were cultured with $2.5 \times 10^{6}$ $\mathrm{BALB} / \mathrm{c}$ BMDCs in six-well plates containing TGF- $\beta(2.5 \mathrm{ng} / \mathrm{ml})$ and/or IL-6 $(20 \mathrm{ng} / \mathrm{ml})$ (Preprotech, London, UK) with or without rHMGB1 $(5 \mu \mathrm{g} / \mathrm{ml})$. To determine the effect of IL-6 on HMGB1-mediated Th17 polarization, we blocked the cultures with an anti-IL-6 Ab $(5 \mu \mathrm{g} / \mathrm{ml})$ or rat IgG followed by flow cytometric analysis of IL-17-producing cells as described above. The production of IL-6, IFN- $\gamma$, and IL-17A in culture supernatants was determined by ELISA kits from eBioscience.

\section{Statistical Analysis}

Data are presented as mean \pm s.d. Group comparisons were performed using Student's $t$-test. $P$-values (two tailed) below 0.05 were considered as statistically significant. Allograft survival curves were generated by the Kaplan-Meier method. Allograft survival (MST) differences between groups were determined using the log-rank test.

\section{RESULTS \\ Kinetics for IL-17 ${ }^{+}$and IFN- $\gamma^{+}$Alloreactive T-Cell Production during Acute Allograft Rejection}

We first sought to determine the kinetics for $\mathrm{IL}_{-}-7^{+}$and IFN $-\gamma^{+}$alloreactive T-cell production during acute allograft rejection. A murine cardiac allograft transplantation model was used to address the question. The recipient mice were kept untreated to allow the development of acute allograft rejection. Splenic T cells were isolated from recipient mice at indicated time after transplantation and then subjected to analysis of $\mathrm{IL}-17^{+}$and IFN- $\gamma^{+}$alloreactive T cells. Interestingly, the alloimmune response after the first 7 days of transplantation was dominated by IL-17-producing $\mathrm{CD} 4{ }^{+}$ and $\mathrm{CD} 8^{+} \mathrm{T}$ cells, with the strongest response noted at day 3 after transplantation (Figure 1a and c). In contrast, a timedependent increase for Th1 alloreactive response was observed characterized by a steady increase of IFN- $\gamma^{+}$cells in $\mathrm{CD}^{+}{ }^{+}$and $\mathrm{CD} 8{ }^{+} \mathrm{T}$ cells from day 1 through days 3,5 , and 7 after transplantation (Figure 1a and d). Both IL-17 ${ }^{+}$ and IFN $-\gamma^{+}$cells in total $\mathrm{CD} 4^{+}$and $\mathrm{CD} 8^{+} \mathrm{T}$ cells were much lower in mice with syngeneic grafts as compared to those with allogeneic grafts (Figure 1b, c, and d). In line with above observations, the highest serum levels for IL-17A were detected in allograft recipient mice at day 3 after transplantation (Figure 1e). Ex vivo studies further indicated that the expansion of $\mathrm{IL}_{-1} 7^{+}$cells in total splenic $\mathrm{CD} 4^{+}$and $\mathrm{CD} 8^{+}$ $\mathrm{T}$ cells is alloantigen specific (Figure 2).

To further confirm the above results, we performed quantitative real-time PCR analysis of HMGB1, IL-6, IL-17, and IFN- $\gamma$ in the cardiac allografts. We observed a timedependent increase of HMGB1 mRNA in allogeneic cardiac grafts from day 1 through days 3, 5, and 7 after transplantation (Figure 3). In agreement, the highest expression level for IL-17 within the grafts was noted at day 3 after transplantation and then receded to a relatively low level, whereas the expression levels for IFN- $\gamma$ showed a steady increase through days 1-7 after transplantation. More interestingly, the expression pattern for IL-6 in the grafts was compatible with that of IL-17 (Figure 3), demonstrating that IL-17 alloreative $\mathrm{T}$ cells are probably the major effector cells implicated in early acute allograft rejection.

\section{IL-17-Producing Alloreactive T Cells Promote Allograft Rejection by Enhancing Neutrophil Infiltration}

To further address the involvement of $\mathrm{CD} 4{ }^{+}$IL-17-producing $\mathrm{T}$ cells in allograft rejection, we performed immunostaining of cardiac allograft sections with FITC-labeled anti-CD4 and PE-labeled anti-IL-17 Abs. CD4 ${ }^{+} \mathrm{IL}-17^{+} \mathrm{T}$ cells were detected in the grafts at day 3 after transplantation, whereas these cells were absent from sections originated from recipients after day 7 of transplantation (Figure 4a). Next, we 

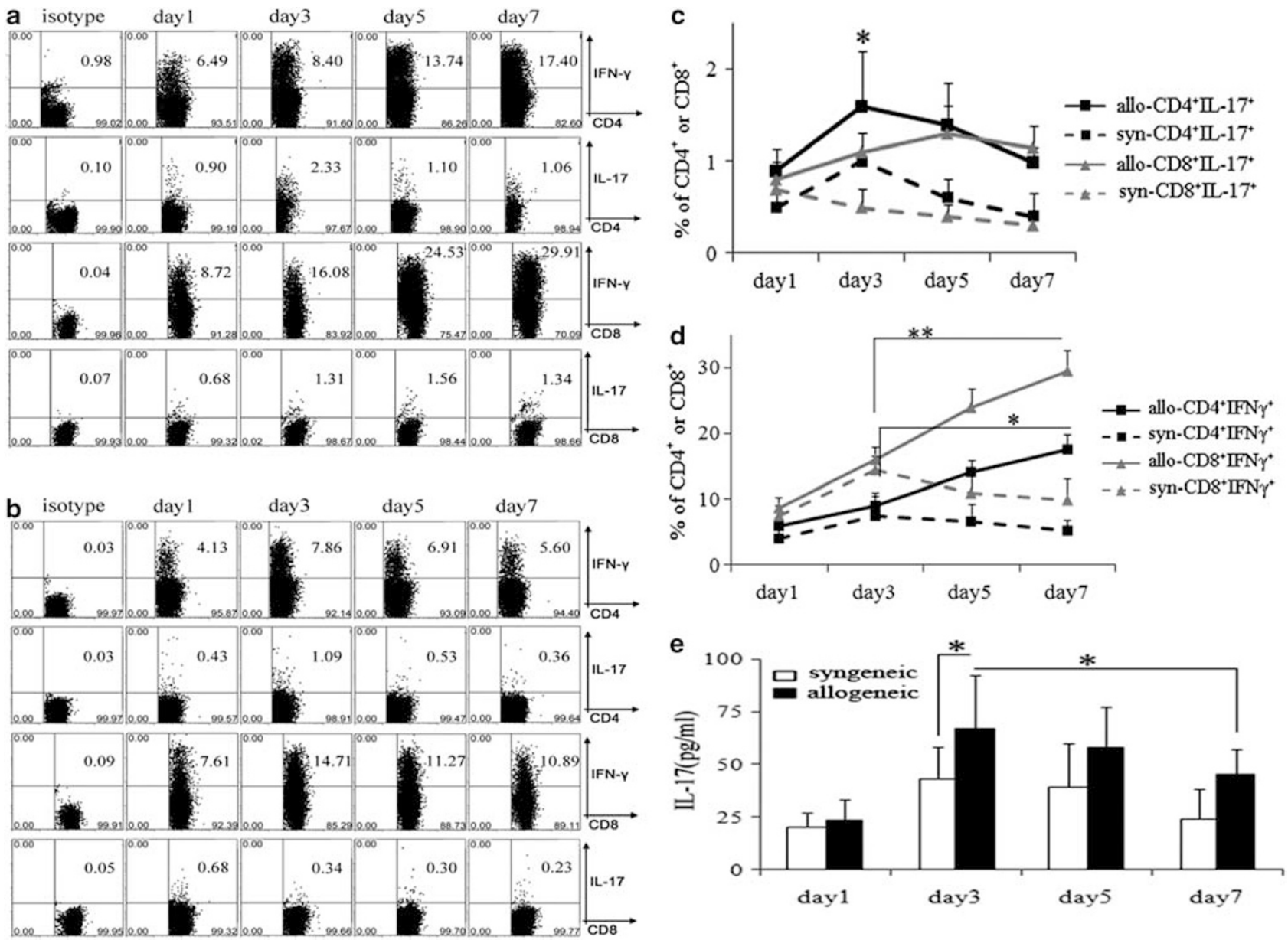

Figure 1 Kinetics for $\mathrm{IL}_{-17^{+}}$and IFN- $\gamma^{+}$splenic alloreactive T-cell production and serum IL-17 levels after cardiac transplantation. Cardiac grafts from $\mathrm{BALB} / \mathrm{c}$ mice were transplanted into C57BL/6 (allogeneic) or BALB/C (syngeneic) mice, splenocytes and serum samples were collected at days 1, 3, 5, and 7 after transplantation. To determine the production of IL-17 and IFN- $\gamma$ by splenic T-cell, we activated splenocytes collected from recipients with allogeneic (a) or syngeneic (b) grafts with PMA $(50 \mathrm{ng} / \mathrm{ml})$ and ionomycin $(1 \mu \mathrm{g} / \mathrm{ml})$ in the presence of monensin $(2 \mu \mathrm{M})$, followed by flow cytometry analysis of intracellular IFN- $\gamma$ and IL-17 expression in CD4 ${ }^{+}$and $\mathrm{CD}^{+}{ }^{+}$T cells. Kinetics for the production of IL-17-producing T cells (c) and IFN- $\gamma$-producing T cells (d) after allogeneic and syngeneic transplantation was plotted from data indicated in (a) and (b). Kinetics for serum IL-17 production of recipients after allogeneic and syngeneic transplantation was determined by ELISA (e). Data are shown as mean \pm s.d. of three independent experiments. ${ }^{*} P<0.05 ;{ }^{*} P<0.01$.

examined inflammatory cell infiltration in the cardiac allografts. It was found that neutrophils were the major infiltrates at the early stage of allograft rejection (ie, on day 3 ), whereas mononuclear cells (eg, monocytes and macrophages) were the major components for late stage of infiltrates (Figure $4 \mathrm{~b}$, c, and d).

\section{HMGB1 Augments CD4 ${ }^{+} \mathrm{IL}-17^{+}$Alloreactive T-Cell Response during Early Acute Allograft Rejection}

Previously, we demonstrated the implication of HMGB1 in acute allograft rejection. ${ }^{22}$ We now sought to address the role of HMGB1 in IL-17-producing alloreactive T-cell response during acute allograft rejection. For this purpose, an HMGB1-neutralizing Ab was i.p. injected into cardiac allograft recipient mice as described. Mice receiving same amount of control IgG served as controls. Blockade of HMGB1 significantly suppressed Th17 response as mani- fested by the decrease of $\mathrm{CD} 4{ }^{+} \mathrm{IL}-17^{+}$alloreactive $\mathrm{T}$ cells after day 3 of transplantation, whereas blockade of HMGB1 showed very minor effect on $\mathrm{CD}^{+}{ }^{+} \mathrm{IL}_{-}-17^{+}$alloreactive $\mathrm{T}$ cells (Figure 5a). Consistently, quantitative RT-PCR analysis of IL-6 and IL-17 in the cardiac allografts at day 3 after transplantation revealed a remarkable decrease of mRNA levels of these cytokines after blockade of HMGB1 (Figure $5 \mathrm{~b})$. In contrast to controls, the infiltration of neutrophils in cardiac allograft was dramatically attenuated upon administration of HMGB1-blocking Ab (Figure 5c). Moreover, blockade of HMGB1 also significantly decreased serum IL$17 \mathrm{~A}$ in recipients after day 3 of transplantation (Figure 5d).

\section{Blockade of IL-17A and HMGB1 Delays Cardiac Allograft Acute Rejection}

To examine directly a link between IL-17 and cardiac allograft rejection as well as neutrophil recruitment, we administered a 

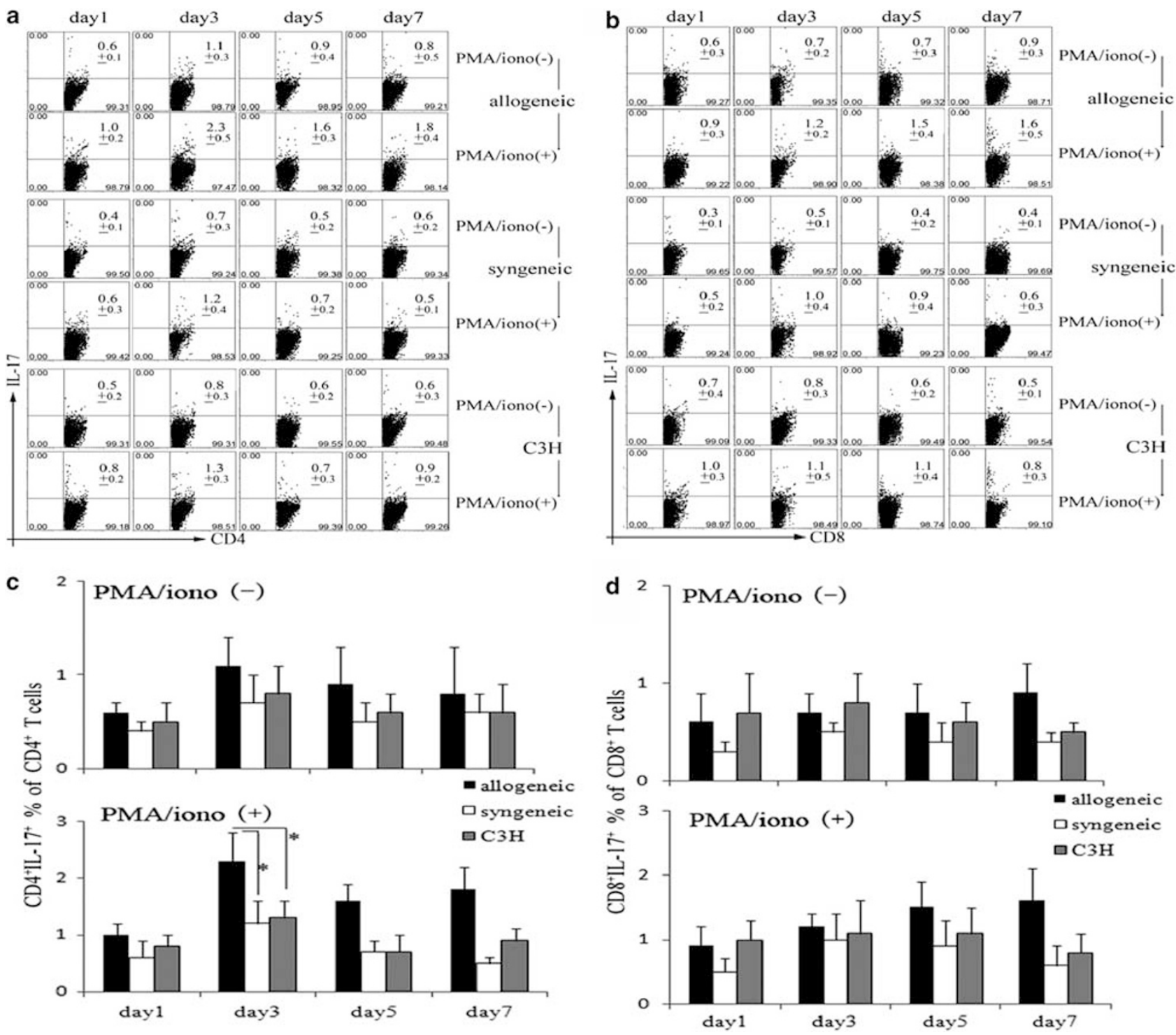

Figure 2 Cardiac allografts induced the production of $\mathrm{IL}-17^{+}$alloantigen-specific T cells. Splenic T cells from each recipient mice were collected as above at each indicated time point. The cells were subjected to ex vivo stimulation using donor (BALB/c) or third party (C3H/HeOuj) splenocytes followed by activation with or without PMA $(50 \mathrm{ng} / \mathrm{ml})$ and ionomycin $(1 \mu \mathrm{g} / \mathrm{ml})$ in the presence of monensin $(2 \mu \mathrm{M})$. Intracellular IL-17 expression was then analyzed by flow cytometry in $\mathrm{CD}^{+}(\mathbf{a}, \mathbf{c})$ and $\mathrm{CD}^{+}(\mathbf{b}, \mathbf{d}) \mathrm{T}$ cells. Data shown in the figure were derived from three independent experiments. ${ }^{\star} P<0.05$.

neutralizing Ab against IL-17A to each recipient i.p. from the day of transplantation until day 3 after transplantation. Mice receiving same amount of control IgG served as controls. Blockade of IL-17A significantly prolonged allograft survival time (MST $=10.25 \pm 0.85$ days; $n=4)$ as compared to that of control mice (MST $=6.4 \pm 0.51$ days; $n=5) \quad\left({ }^{\star} P<0.05\right.$; Figure 6a). In line with this result, IL-17A-neutralizing $\mathrm{Ab}$ treatment significantly attenuated neutrophil infiltration (Figure 6b). Recipients treated with anti-HMGB1 Abs had a significant longer allograft survival time $(\mathrm{MST}=13.83 \pm 0.6$ days; $n=6)$ as compared to that of recipients treated with rabbit IgG $(\mathrm{MST}=7.16 \pm 0.6$ days; $n=6)\left({ }^{*} P<0.01\right.$; Figure $6 c)$. Consistently, flow cytometry revealed that administration of anti-HMGB1 Abs also significantly decreased the percentage of splenic alloreactive IFN- $\gamma$-producing $\mathrm{CD} 8^{+} \mathrm{T}$ cells in recipients compared with that of controls $\left({ }^{\star} P<0.05\right.$; Figure 6d).

\section{HMGB1 Polarizes Th17 Response by Stimulating DC Secretion of IL-6}

As HMGB1 has been shown to be potent to stimulate myeloid and plasmacytoid DC maturation and cytokine secretion, ${ }^{26,27}$ we hypothesized that HMGB1 may augment Th17 response by stimulating DC secretion of cytokines (eg, TGF- $\beta$ and/or IL-6) relevant to Th17 development. To address this hypothesis, we established MLC assays by using BMDCs derived from donor mice and splenic $\mathrm{T}$ cells received from recipient mice. BMDCs were co-cultured with recipient- 

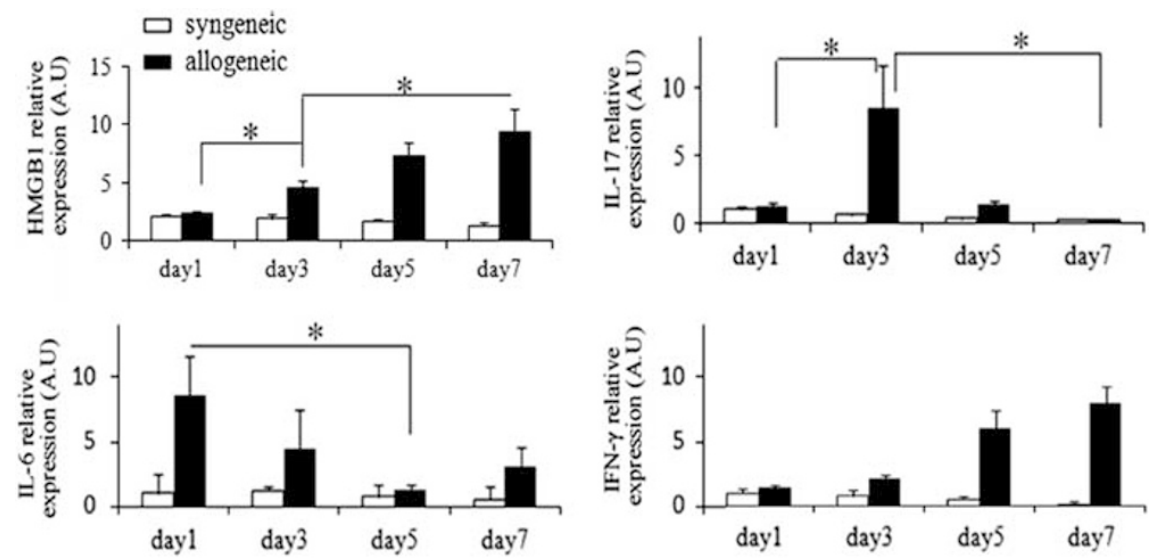

Figure 3 RT-PCR analysis of HMGB1, IL-6, IL-17, and IFN- $\gamma$ mRNA in the cardiac grafts. Allogeneic or syngeneic grafts were collected at days 1, 3, 5, and 7 after transplantation. Total RNAs were prepared and subjected to real-time RT-PCR analysis of each indicated cytokine as described. Three mice were included in each time point. ${ }^{\star} P<0.05$.

a

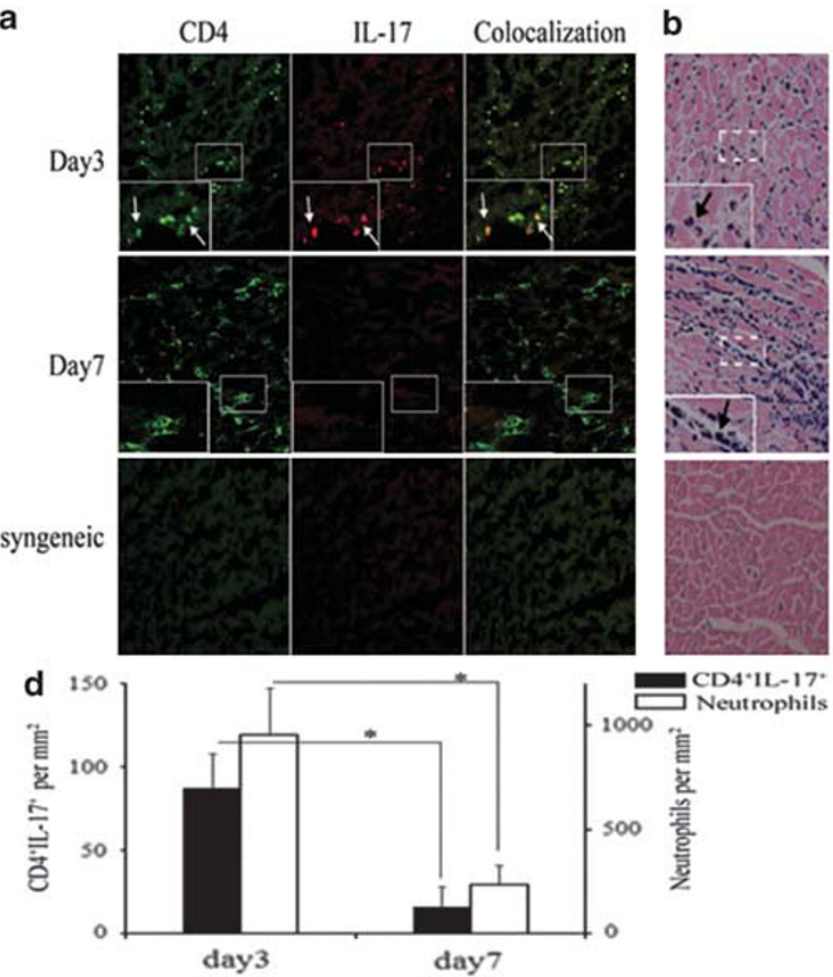

C

CD4

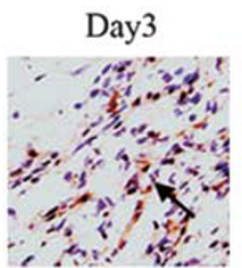

Day7

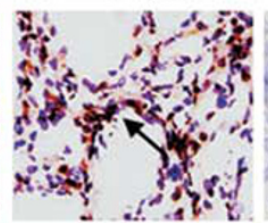

CD8
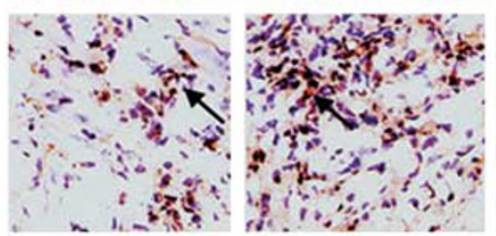

syngeneic

Gr-1
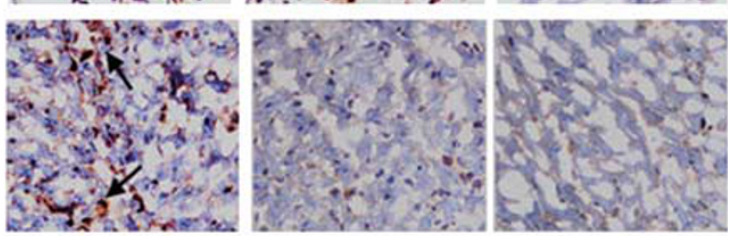

$\mathrm{F} 4 / 80$
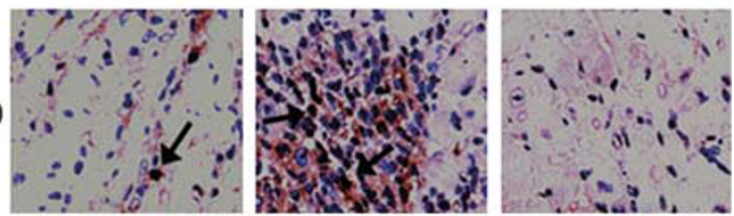

Figure 4 Histological and immunohistochemical analysis of cardiac allografts. Allogeneic or syngeneic grafts were collected at days 3 and 7 after transplantation. (a) Tissue cryostat sections (original magnification, $\times 200$ ) were co-stained for CD4 and IL-17. CD4 ${ }^{+} \mathrm{IL}-17^{+} \mathrm{T}$ cells were present in allografts at day 3 after transplantation (upper panel), whereas they were undetectable in allografts at day 7 after transplantation (middle panel), or syngeneic grafts at days 3 and 7 after transplantation (lower panel). (b) Leukocyte infiltration in allogeneic and syngeneic cardiac grafts. Compare to syngeneic grafts, copious amount of neutrophil infiltration was noted in allografts at day 3 after transplantation (upper panel), whereas dominant mononuclear cell infiltration was observed at day 7 after transplantation (middle panel). (c) Immunostaining results. The sections were stained for CD4, CD8, Gr-1, or $\mathrm{F} 4 / 80$ to further confirm the infiltration of $\mathrm{CD}^{+}, \mathrm{CD}^{+}$T cells, neutrophils or monocytes/macrophages in allogeneic or syngeneic cardiac grafts at days 3 and 7 after transplantation. (d) The quantification of cellular infiltrates (CD4 ${ }^{+} \mathrm{IL}-17^{+} \mathrm{T}$ cells and neutrophils). Data from one representative out of three experiments are shown. ${ }^{*} P<0.05$.

derived splenic $\mathrm{T}$ cells in the presence of HMGB1, TGF- $\beta$, and/or IL-6. Cultures in the presence of LPS were used as positive controls. As expected, the addition of TGF- $\beta$ and IL-6 significantly promoted the generation of $\mathrm{CD} 4^{+} \mathrm{IL}-17^{+}$ alloreactive $\mathrm{T}$ cells (Figure 7a). Of note, HMGB1 showed high potency to promote the production of both $\mathrm{CD}_{4}^{+}$and $\mathrm{CD}^{+}$IL-17-producing cells as compared to that of cells cultured with TGF- $\beta$ only. HMGB1 is also potent to augment 
a

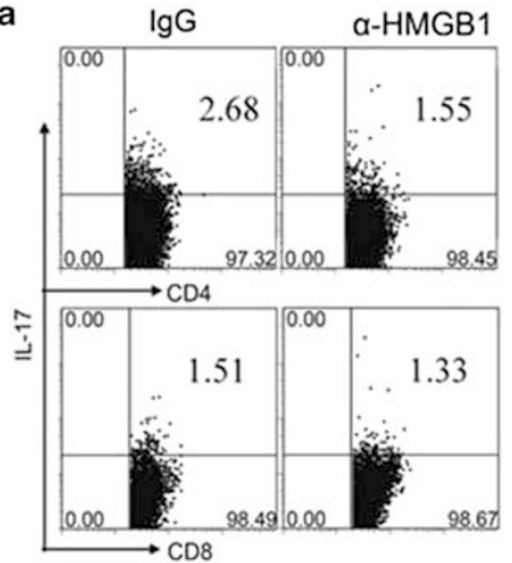

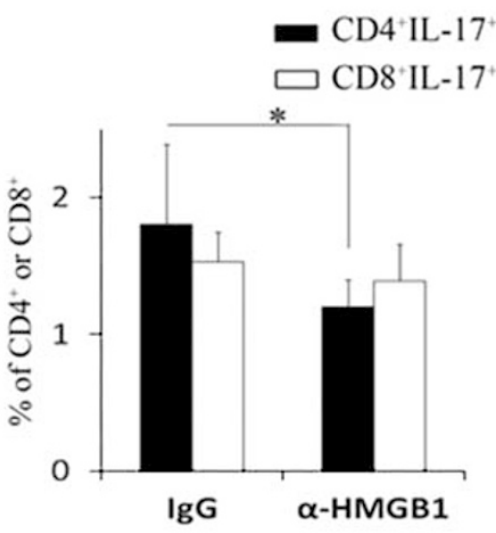

C

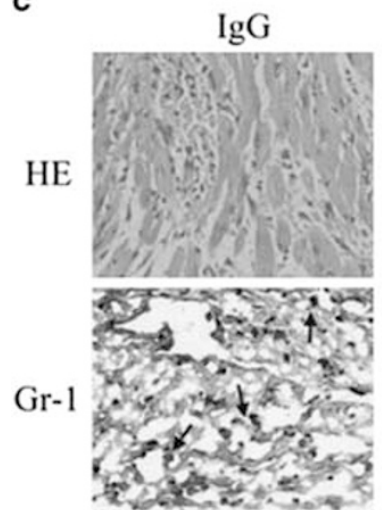

$\alpha-\mathrm{HMGB} 1$

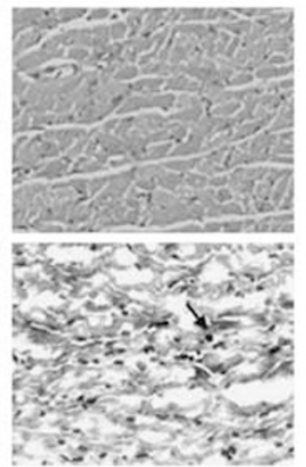

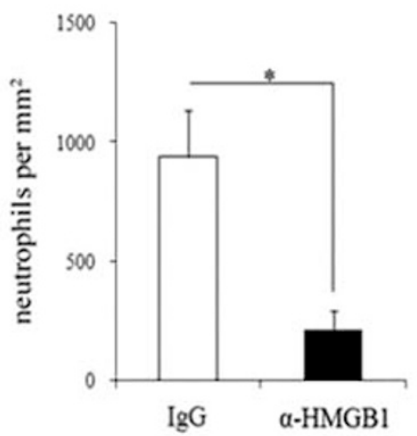

b
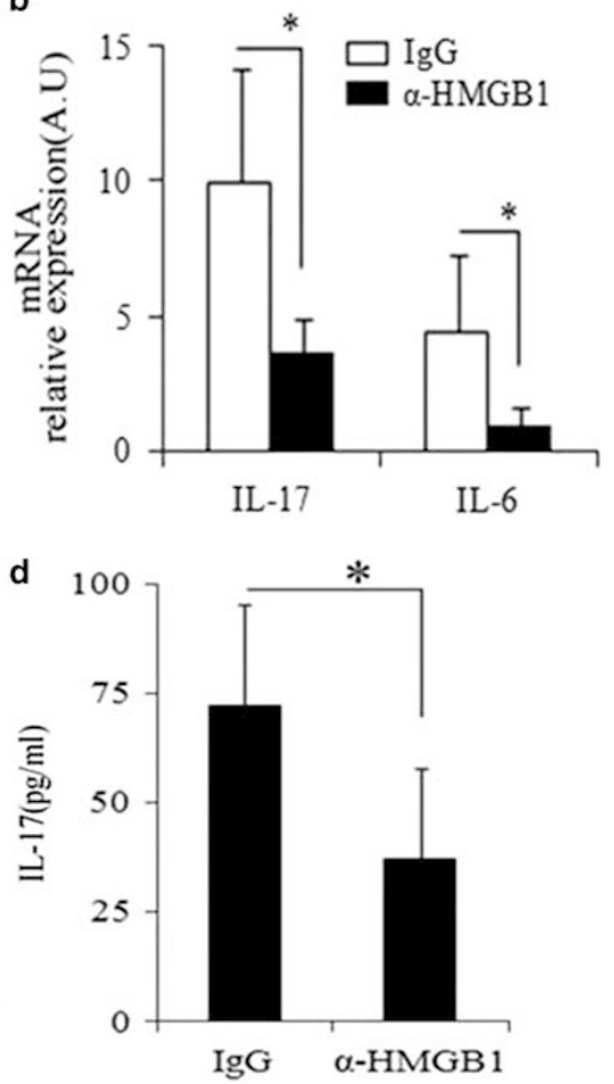

Figure 5 Blockade of HMGB1 suppresses IL-17 ${ }^{+}$T-cell production. Recipient mice $(n=5)$ were i.p. injected with either anti-HMGB1 Ab or rabbit lgG from the day before transplantation till day 3 after transplantation, spleens were then collected. (a) The capacities of IL-17 secretions by splenic T cells activated with PMA/ionomycin were analyzed by intracellular cytokines staining. The experiment was repeated three times, a similar result was obtained. Significant differences as calculated by $t$-test are indicated by an asterisk $\left({ }^{*} P<0.05\right)$. (b) Quantitative real-time PCR was performed to evaluate the effects of HMGB1 on IL-17 and IL-6 expression in the cardiac allografts at day 3 after transplantation. Results shown are averages from three independent experiments ( \pm s.d). Significant differences as calculated by $t$-test are indicated by an asterisk $\left({ }^{*} P<0.05\right)$. (c) Histological analysis was performed to examine the infiltration of neutrophils in cardiac allograft following HMGB1-blocking antibody or control IgG treatment. Formalin-fixed paraffin sections were stained with hematoxylin and eosin (original magnification, $\times 200$ ). Immunohistochemistry with anti-Gr-1 antibody was conducted to further confirm the infiltration of neutrophils in cardiac allograft following administration of anti-HMGB1-blocking antibody or control lgG. (d) Administration of HMGB1-neutralizing antibody significantly decreased serum IL-17A in allograft recipients ( $n=4-5$ mice per group). Serum samples were collected from recipients treated with either HMGB1 neutralizing antibody or control lgG at day 3 after transplantation. IL-17A was analyzed by ELISA. Results shown are averages from three independent experiments ( \pm s.d). Significant differences as calculated by $t$-test are indicated by an asterisk $\left({ }^{\star} P<0.05\right)$.

the production of $\mathrm{CD}^{+}{ }^{+} \mathrm{IFN}-\gamma^{+} \mathrm{T}$ cells (Figure $7 \mathrm{~b}$ ). To tackle the underlying mechanism, we added an IL-6-neutralizing $\mathrm{Ab}$ into the culture system. Remarkably, blockade of IL- 6 abolished the regulatory effect of HMGB1 on IL-17 ${ }^{+}$ T-cell production (Figure $7 \mathrm{~b}$ ).

To further examine the implication of IL-6 in HMGB1mediated Th17 response, we examined the capacity of HMGB1 to induce BMDCs secretion of IL-6. Similar to LPS, HMGB1 is also potent to stimulate BMDCs secretion of IL-6 (Figure $8 \mathrm{a}$ ). We then checked IL-6 production of supernatants from MLC in the presence of HMGB1, and similar results were obtained (Figure $8 \mathrm{~b}$ ). It is noteworthy that IL-17 production was enhanced in MLC assays stimulated with HMGB1 in the presence of TGF- $\beta$ (Figure $8 \mathrm{c}$ ). In contrast, TGF- $\beta$ showed very limited effect on IFN- $\gamma$ secretion in MLC assays stimulated by HMGB1 (Figure $8 \mathrm{~d}$ ), which could be due to its anti-inflammatory effect.

\section{DISCUSSION}

In this study, we have shown that alloreactive Th1 and Th17 responses exhibit a differential kinetics in the process of cardiac allograft rejection. Our study results demonstrate that HMGB1 plays a pivotal role in the induction of IL-17-producing alloreactive $\mathrm{T}$ cells by stimulating DCs secretion of IL-6. There is increasing evidence that acute allograft rejection might be triggered by different types of helper $\mathrm{T}$ cells acting through redundant or synergistic pathways. Indeed, Th1 responses initiate allograft rejection by promoting cytotoxic T-cell activities and IFN- $\gamma$-mediated delayed-type hypersensitivity reactions. ${ }^{28}$ Th2 cells activated through indirect 

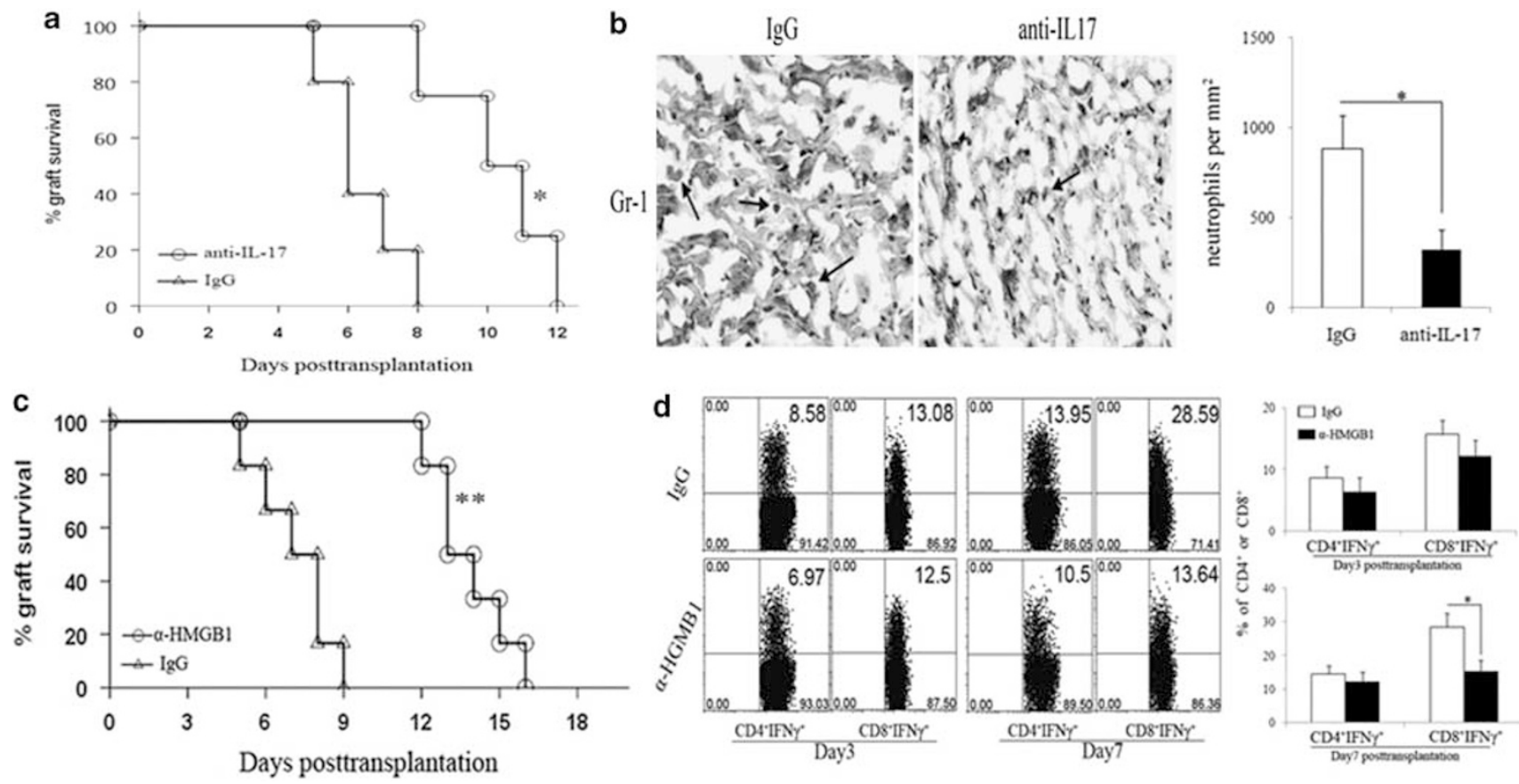

Figure 6 Blockade of IL-17A and HMGB1 significantly prolongs cardiac allograft survival (a) Recipients $(n=4)$ were treated with $100 \mu \mathrm{g}$ per day of anti-IL-17A mAb from the day of transplantation and the following 3 consecutive days. The same amount of rat lgG was administered to recipients $(n=5)$ as controls. Recipients treated with anti IL-17A mAb had a significant longer allograft survival time (MST $=10.25 \pm 0.85$ days) as compared with that of recipients treated with rat IgG (MST $=6.4 \pm 0.51$ days) $\left({ }^{*} P<0.05\right)$. (b) Immunohistochemistry with anti-Gr- 1 antibody was conducted to evaluate the infiltration of neutrophils in cardiac allograft following administration of IL-17A-blocking antibody or control rat IgG. $\left({ }^{*} P<0.05\right)$. (c) HMGB1-neutralizing $\mathrm{Ab}(600 \mu \mathrm{g}$ per mouse) was i.p. injected daily into recipients $(n=6)$ from the day before transplantation till day 4 after transplantation. Mice $(n=6)$ receiving same amount of normal rabbit IgG (Sigma-Aldrich) served as controls. Recipients treated with anti-HMGB1 Abs had a significantly longer allograft survival time (MST $=13.83 \pm 0.6$ days) as compared to that of recipients treated with rabbit lgG (MST $=7.16 \pm 0.6$ days) $\left({ }^{* * P}<0.01\right)$. (d) Splenic T cells from each recipient mice were collected as above at each indicated time point. Cells were stimulated for $4.5 \mathrm{~h}$ with PMA $(50 \mathrm{ng} / \mathrm{ml})$ and ionomycin $(1 \mu \mathrm{g} / \mathrm{ml})$ in

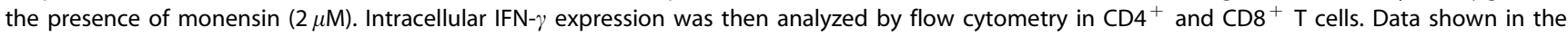
figure were derived from three independent experiments. ${ }^{\star} P<0.05$.

allorecognition can exert dual effects on acute and chronic rejection of allogeneic transplants. ${ }^{29}$ The newly identified Th17 subset, which preferentially produces IL-17, is also endowed with potent proinflammatory properties, and it is also very likely involved in transplant rejection. ${ }^{3}$ We now demonstrated experimental evidence indicating that Th17 alloreactive response has a key function at the early stage of allograft rejection, in advance of the allograft destruction caused by IFN- $\gamma$-producing Th1 cells. Of note, the compatible IL-6 expression pattern as IL-17 observed in the allografts may represent a critical factor facilitating the generation of IL-17-producing T cells. Conversely, an overwhelming IFN- $\gamma$ production (Th1 response) at the late stage of allorejection suppressed Th17 response. These findings also agree with a recent report that that Th17 cells have a disease-promoting function at the early stage of corneal allograft rejection. ${ }^{30}$ Furthermore, in line with our results, it has been shown that in addition to IL-1 $\alpha$, HMGB1 as a second mediator released from damaged human endothelial cells modulates alloreactive T-cell IFN- $\gamma$ and IL-17 production. Interestingly, HMGB1 functions by inducing IL-1 $\beta$ secretion from monocytes through TLR4 and CD14. ${ }^{31}$
Our data indicate that HMGB1 also enhances Th17 alloreactive response by inducing IL-6 production from DCs.

It has been shown that IL-17 acts as a potent proinflammatory cytokine to induce tissue damage at least in part through neutrophil recruitment. ${ }^{3,28}$ Activated neutrophils have been suggested to have significant implications in the pathogenesis of allograft rejection. ${ }^{32}$ Combining our observations together with others, ${ }^{31}$ we propose that Th17 alloreactive response provides a rapid influx of neutrophils into the grafts, which then mediate early graft damage when the development of IFN- $\gamma$-producing T cells is still at the early stage. However, once these IFN- $\gamma$-producing $\mathrm{T}$ cells are dominant at the late stage of rejection, resulting in the influx of monocyte/macrophages into the grafts, the actions of IL17-producing $\mathrm{T}$ cells are then receded to a relatively low level.

More recently, IL-17 has been implicated in rejection of lung, cardiac transplants, as well as graft-vs-host disease (GVHD). It has been demonstrated that a population of type (V) collagen-specific lymphocytes could induce IL-17 expression and mediate graft rejection in a rat lung transplantation model. ${ }^{33}$ This finding is supported by clinical observations: prospective monitoring of human lung trans- 

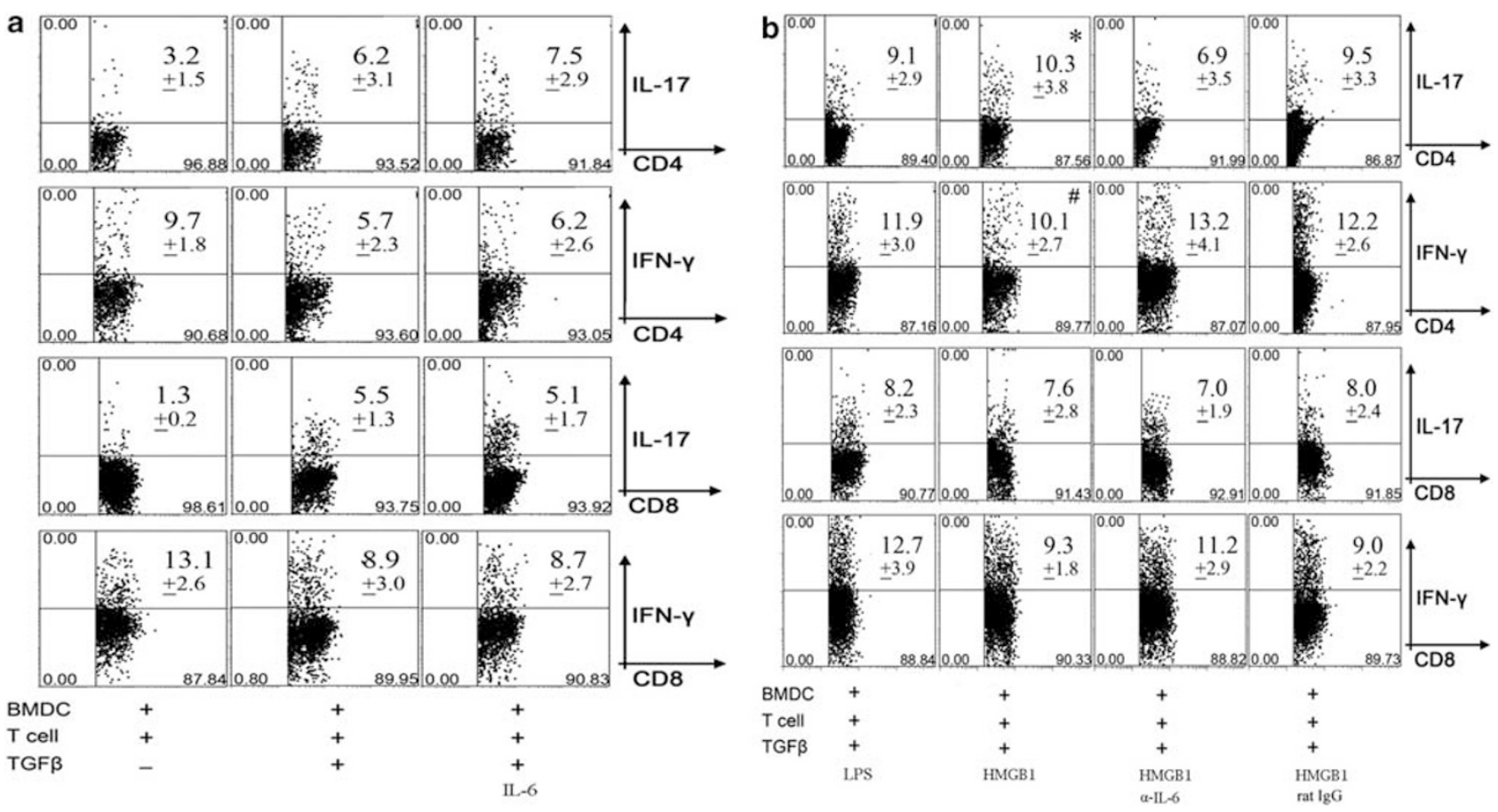

Figure 7 HMGB1 promotes IL-17-producing T-cell production in MLC. (a) To examine the development of IL-17- and IFN- $\gamma$-producing T cells in alloimmunity, we performed MLC to test the regulatory effect of exogenous TGF- $\beta$ and IL- 6 on the generation of these T-cell subsets. (b) To demonstrate the regulatory effect of HMGB1, LPS, and IL- 6 on the generation of IL-17- and IFN- $\gamma$-producing T cells in alloimmunity, we added HMGB1 or LPS into MLC with or without anti-IL-6 Ab. In both cases, the cells were restimulated with PMA/ionomycin and then subjected to intracellular staining of IL-17 and IFN- $\gamma$ followed by flow cytometry analysis. Results shown in the figure were derived from three independent experiments. ${ }^{\star} P<0.05$ vs BMDC/T cell/TGF- $\beta$ and BMDC/T cell/ TGF- $\beta / \alpha-$ IL- $6 ;{ }^{\#} P<0.05$ vs BMDC/T cell/TGF- $\beta$.
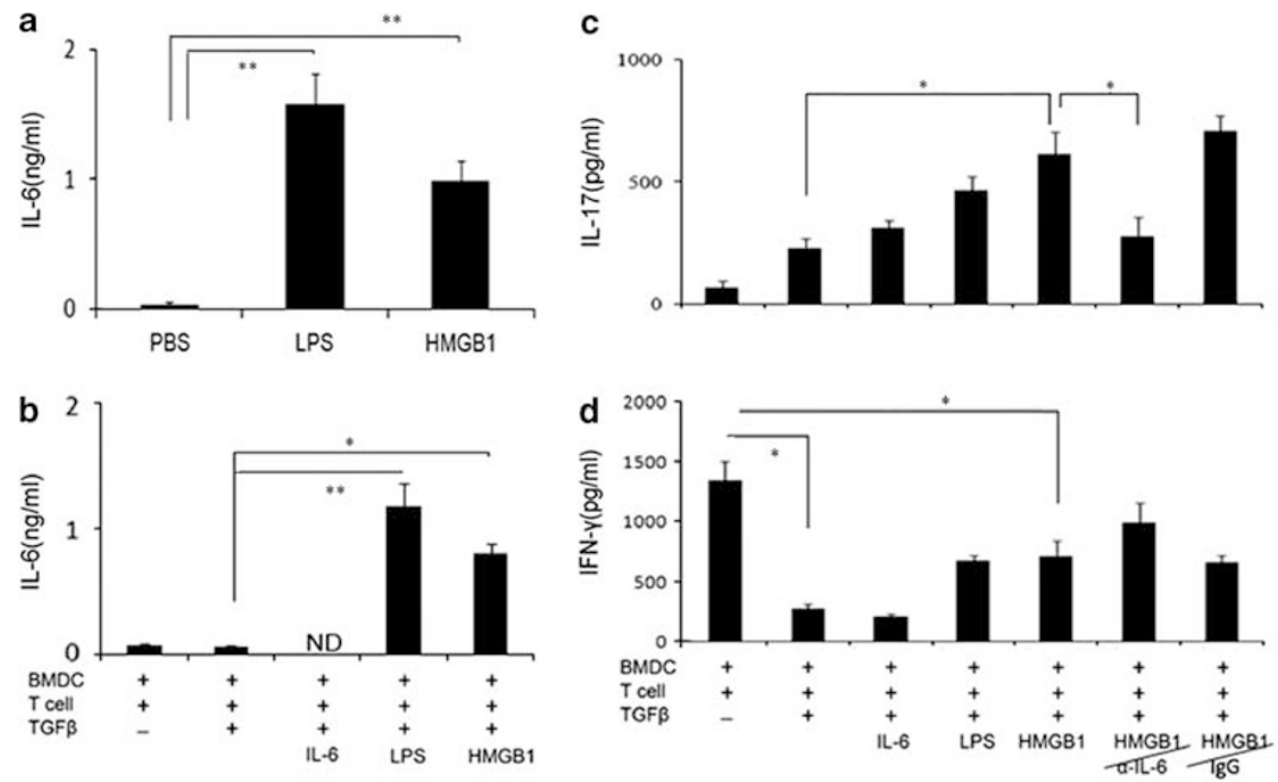

Figure 8 HMGB1 promotes the production of IL-17-producing T cells by stimulating DC secretion of IL-6. (a) To determine the stimulatory capacity of HMGB1 in BMDCs for the production of IL-6, we cultured $1 \times 10^{6}$ BMDCs in the presence of LPS (500 ng/ml), HMGB1 (5 $\left.\mu \mathrm{g} / \mathrm{ml}\right)$, or control vehicle for $18 \mathrm{~h}$. Supernatants were then collected for ELISA of IL-6. In the MLC described in Figure 7, ELISA was performed to determine the amount of IL-6 (b), IL-17(c), and IFN- $\gamma$ (d) in the supernatants of co-cultures at each indicated culture condition. ND stands for do not detect. Results shown are averages from three independent experiments $\left( \pm\right.$ s.d.). ${ }^{\star} P<0.05 ;{ }^{* *} P<0.01$. 
plant patients revealed a critical role of collagen $(\mathrm{V})$-specific cellular immunity in the progression of obliterative bronchiolitis, and an interplay between Th17 cells and monocytes is critically important in this allograft-induced autoimmune response. ${ }^{34}$ Moreover, pretransplant patients who show collagen $(\mathrm{V})$ reactivity have an increased incidence of early graft dysfunction following transplantation. ${ }^{35}$ Most recently, two groups have shown that a highly purified population of Th17 cells is capable of inducing lethal GVHD, hallmarked by extensive pathologic cutaneous and pulmonary lesions. ${ }^{36}$ IL-17 is dispensable for GVHD and graft $v s$ tumor activity by whole $\mathrm{T}$ cells, but contributes to the early development of CD4-mediated GVHD by promoting production of proinflammatory cytokines. ${ }^{37}$ Interestingly, recent studies indicated that IL-17 functions as a critical inflammatory cytokine to mediate cardiac allograft rejection and vasculopathy in T-bet $^{-l-}$ mice. These results further support our finding that $\mathrm{CD} 4^{+} \mathrm{Th} 17$ may have an important role in the alloimmunity settings in the absence of Th1-mediated alloimmune response. ${ }^{38}$

As an innate alarmin, HMGB1 is implicated in the initiation of inflammatory response following acute, local organ injury. ${ }^{39}$ HMGB1 is also evident in the pathogenesis of some autoimmune disorders characterized by altered Th17 responses such as multiple sclerosis, rheumatoid arthritis, and experimental autoimmune encephalomyelitis. ${ }^{40}$ In line with these reports, we have previously demonstrated that high amount of HMGB1 can be passively released by damaged cells of allografts and actively secreted by allograftinfiltrated immune cells such as DCs and macrophages. ${ }^{22}$ In this study, we also detected a time-dependent increase of HMGB1 mRNA in allogeneic cardiac grafts after transplantation. Nevertheless, considering organ collection and ischemia/reperfusion insults result in passive release of HMGB1 by damaged cells of allografts, HMGB1 may contribute the initiation of alloimmune response at a fast kinetics than that observed at the mRNA levels. Notably, we observed that blockade of HMGB1 exhibited higher potency than neutralization of IL-17 in terms of attenuation of neutrophil infiltration, which could be due to that HMGB1 may drive neutrophil recruitment synergistically along with IL-17. Interestingly, consistent with our previous observation that rA-box treatment delays cardiac allograft rejection, ${ }^{22}$ we found that administration of anti-HMGB1 Abs also prolongs allograft survival, which is associated with inhibition of both alloreactive Th17 and IFN- $\gamma$-producing $\mathrm{CD}^{+}{ }^{+} \mathrm{T}$ cells. Together, for the first time, we provide direct evidence suggesting that HMGB1 is implicated in the regulation of Th17 response during early acute allograft rejection.

In summary, our studies demonstrated that HMGB1 released by APCs (DC, macrophage) and necrotic cells in the early phase of transplantation promotes APC activation and IL-6 production, which then work together with TGF- $\beta$ to polarize Th17 response. Altered IL-17 production within the allografts would recruit neutrophils to mediate tissue damage. Likewise, with the progress of alloimmune response, Th1 response induced by IL-12 would have a dominant role in the late phase of acute allograft rejection. Therefore, blockade of HMGB1 at the early stage of alloimmune response could be an effective strategy to minimize allograft damage by suppressing Th17 alloreactive response.

\section{ACKNOWLEDGEMENTS}

This work was supported by the National Natural Science Foundation of China (30772039 to M Fang), NSFC-Guangdong Union Grant (U0832003 to M Fang and FL Gong), and the Ministry of Science and Technology of China (2007CB512402 to F Gong and M Fang).

\section{DISCLOSURE/CONFLICT OF INTEREST}

The authors declare no conflict of interest.

1. McGeachy MJ, Cua DJ. Th17 cell differentiation: the long and winding road. Immunity 2008;28:445-453.

2. Cua DJ, Sherlock J, Chen Y, et al. Interleukin-23 rather than interleukin12 is the critical cytokine for autoimmune inflammation of the brain. Nature 2003;421:744-748.

3. Ouyang W, Kolls JK, Zheng Y. The biological functions of T helper 17 cell effector cytokines in inflammation. Immunity 2008;28:454-467.

4. Veldhoen M, Hocking RJ, Atkins $\mathrm{CJ}$, et al. TGFbeta in the context of an inflammatory cytokine milieu supports de novo differentiation of IL-17producing T cells. Immunity 2006;24:179-189.

5. Mangan PR, Harrington LE, O'Quinn DB, et al. Transforming growth factor-beta induces development of the $T(H) 17$ lineage. Nature 2006;441:231-234.

6. Ivanov II, McKenzie BS, Zhou L, et al. The orphan nuclear receptor RORgammat directs the differentiation program of proinflammatory IL-17+ T helper cells. Cell 2006;126:1121-1133.

7. Yang XO, Pappu BP, Nurieva R, et al. T helper 17 lineage differentiation is programmed by orphan nuclear receptors ROR alpha and ROR gamma. Immunity 2008;28:29-39.

8. Korn T, Bettelli E, Gao W, et al. IL-21 initiates an alternative pathway to induce proinflammatory $\mathrm{T}(\mathrm{H}) 17$ cells. Nature 2007;448:484-487.

9. Bettelli E, Carrier Y, Gao W, et al. Reciprocal developmental pathways for the generation of pathogenic effector TH17 and regulatory T cells. Nature 2006;441:235-238.

10. Murphy $\mathrm{CA}$, Langrish $\mathrm{CL}, \mathrm{Chen} \mathrm{Y}$, et al. Divergent pro- and antiinflammatory roles for IL-23 and IL-12 in joint autoimmune inflammation. J Exp Med 2003;198:1951-1957.

11. Langrish $\mathrm{CL}$, Chen $\mathrm{Y}$, Blumenschein $\mathrm{WM}$, et al. IL-23 drives a pathogenic T cell population that induces autoimmune inflammation. J Exp Med 2005;201:233-240.

12. Yen $\mathrm{D}$, Cheung J, Scheerens $\mathrm{H}$, et al. IL-23 is essential for $\mathrm{T}$ cellmediated colitis and promotes inflammation via IL-17 and IL-6. J Clin Invest 2006;116:1310-1316.

13. Lee $E$, Trepicchio $W L$, Oestreicher JL, et al. Increased expression of interleukin 23 p19 and p40 in lesional skin of patients with psoriasis vulgaris. J Exp Med 2004;199:125-130.

14. Braun RK, Molitor-Dart M, Wigfield C, et al. Transfer of tolerance to collagen type $V$ suppresses T-helper-cell-17 lymphocyte-mediated acute lung transplant rejection. Transplantation 2009;88:1341-1348.

15. Antonysamy MA, Fanslow WC, Fu F, et al. Evidence for a role of IL-17 in organ allograft rejection: IL-17 promotes the functional differentiation of dendritic cell progenitors. J Immunol 1999;162:577-584.

16. Van Kooten C, Boonstra JG, Paape ME, et al. Interleukin-17 activates human renal epithelial cells in vitro and is expressed during renal allograft rejection. J Am Soc Nephrol 1998;9:1526-1534.

17. Vanaudenaerde BM, Dupont $\sqcup$, Wuyts $W A$, et al. The role of interleukin-17 during acute rejection after lung transplantation. Eur Respir J 2006;27:779-787.

18. Bustin M. Regulation of DNA-dependent activities by the functional motifs of the high-mobility-group chromosomal proteins. Mol Cell Biol 1999;19:5237-5246.

19. Scaffidi $P$, Misteli $T$, Bianchi ME. Release of chromatin protein HMGB1 by necrotic cells triggers inflammation. Nature 2002;418:191-195. 
20. Muller $S$, Scaffidi $P$, Degryse $B$, et al. New EMBO members' review: the double life of HMGB1 chromatin protein: architectural factor and extracellular signal. EMBO J 2001;20:4337-4340.

21. Ulloa L, Messmer D. High-mobility group box 1 (HMGB1) protein: friend and foe. Cytokine Growth Factor Rev 2006;17:189-201.

22. Huang $\mathrm{Y}$, Yin $\mathrm{H}$, Han J, et al. Extracellular hmgb1 functions as an innate immune-mediator implicated in murine cardiac allograft acute rejection. Am J Transplant 2007;7:799-808.

23. Han J, Zhong J, Wei W, et al. Extracellular high-mobility group box 1 acts as an innate immune mediator to enhance autoimmune progression and diabetes onset in NOD mice. Diabetes 2008;57:2118-2127.

24. Yu G, Dai H, Chen J, et al. Gene delivery of indoleamine 2,3-dioxygenase prolongs cardiac allograft survival by shaping the types of T-cell responses. J Gene Med 2008;10:754-761.

25. Lutz MB, Kukutsch N, Ogilvie AL, et al. An advanced culture method for generating large quantities of highly pure dendritic cells from mouse bone marrow. J Immunol Methods 1999;223:77-92.

26. Messmer D, Yang H, Telusma G, et al. High mobility group box protein 1: an endogenous signal for dendritic cell maturation and Th1 polarization. J Immunol 2004;173:307-313.

27. Dumitriu IE, Baruah $\mathrm{P}$, Bianchi ME, et al. Requirement of HMGB1 and RAGE for the maturation of human plasmacytoid dendritic cells. Eur J Immunol 2005;35:2184-2190.

28. Goriely S, Goldman M. The interleukin-12 family: new players in transplantation immunity? Am J Transplant 2007;7:278-284.

29. Illigens BM, Yamada A, Anosova $N$, et al. Dual effects of the alloresponse by Th1 and Th2 cells on acute and chronic rejection of allotransplants. Eur J Immunol 2009;39:3000-3009.

30. Chen $\mathrm{H}$, Wang $\mathrm{W}$, Xie $\mathrm{H}$, et al. A pathogenic role of IL- 17 at the early stage of corneal allograft rejection. Transpl Immunol 2009;21:155-161.
31. Rao DA, Tracey KJ, Pober JS. IL-1alpha and IL-1beta are endogenous mediators linking cell injury to the adaptive alloimmune response. J Immunol 2007:179:6536-6546.

32. Miura M, El-Sawy T, Fairchild RL. Neutrophils mediate parenchymal tissue necrosis and accelerate the rejection of complete major histocompatibility complex-disparate cardiac allografts in the absence of interferon-gamma. Am J Pathol 2003;162:509-519.

33. Yoshida $S$, Haque A, Mizobuchi T, et al. Anti-type V collagen lymphocytes that express IL-17 and IL-23 induce rejection pathology in fresh and well-healed lung transplants. Am J Transplant 2006;6:724-735.

34. Burlingham WJ, Love RB, Jankowska-Gan E, et al. IL-17-dependent cellular immunity to collagen type $\mathrm{V}$ predisposes to obliterative bronchiolitis in human lung transplants. J Clin Invest 2007;117:3498-3506.

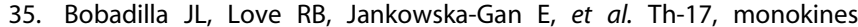
collagen type $\mathrm{V}$, and primary graft dysfunction in lung transplantation. Am J Respir Crit Care Med 2008;177:660-668.

36. Carlson MJ, West ML, Coghill JM, et al. In vitro-differentiated TH17 cells mediate lethal acute graft-versus-host disease with severe cutaneous and pulmonary pathologic manifestations. Blood 2009;113:1365-1374.

37. Kappel LW, Goldberg GL, King CG, et al. IL-17 contributes to CD4mediated graft-versus-host disease. Blood 2009;113:945-952.

38. Yuan X, Paez-Cortez J, Schmitt-Knosalla I, et al. A novel role of CD4 Th17 cells in mediating cardiac allograft rejection and vasculopathy. J Exp Med 2008;205:3133-3144.

39. Tsung A, Sahai $R$, Tanaka $H$, et al. The nuclear factor HMGB1 mediates hepatic injury after murine liver ischemia-reperfusion. J Exp Med 2005:201:1135-1143.

40. Andersson A, Covacu R, Sunnemark D, et al. Pivotal advance: HMGB1 expression in active lesions of human and experimental multiple sclerosis. J Leukoc Biol 2008;84:1248-1255. 